\title{
A System and Methodology for Measuring Volatile Organic Compounds Produced by Hydroponic Lettuce in a Controlled Environment
}

\author{
Craig S. Charron ${ }^{1}$ and Daniel J. Cantliffe ${ }^{2}$ \\ Horticultural Sciences Department, University of Florida, Gainesville, FL 32611
}

\author{
Raymond M. Wheeler ${ }^{3}$ \\ National Aeronautics and Space Administration, Mail Code MD-RES, Kennedy Space Center, FL 32899
}

\author{
Ara Manukian ${ }^{4}$ and Robert R. Heath ${ }^{5}$ \\ United States Department of Agriculture, Agricultural Research Service, Gainesville, FL 32604
}

Additional index words. (Z)-3-hexenal, (Z)-3-hexenol, (Z)-3-hexenyl acetate

\begin{abstract}
A system and methodology were developed for the nondestructive qualitative and quantitative analysis of volatile emissions from hydroponically grown 'Waldmann's Green' leaf lettuce (Lactuca sativa L.). Photosynthetic photon flux (PPF), photoperiod, and temperature were automatically controlled and monitored in a growth chamber modified for the collection of plant volatiles. The lipoxygenase pathway products $(Z)$-3-hexenal, $(Z)$-3-hexenol, and $(Z)$-3-hexenyl acetate were emitted by lettuce plants after the transition from the light period to the dark period. The volatile collection system developed in this study enabled measurements of volatiles emitted by intact plants, from planting to harvest, under controlled environmental conditions.
\end{abstract}

Several methods for collecting volatile compounds from plants have been used. Vacuum and steam distillation techniques have been used to extract volatiles from detached plant tissue but can lead to the production of damage-related volatiles (Buttery and Ling, 1984). Buttery et al. (1985) severed wheat plants at their bases and placed the leaves with stems into a flask; air purified by activated charcoal flowed over the plant material and then through a Tenax trap onto which the plant volatiles were adsorbed. Heath et al. (1992) demonstrated that the relative amounts of volatiles produced by flowers from cut branches of night-blooming jessamine (Cestrum nocturnum L.) differed from those of flowers from intact branches.

Methods used for collecting volatiles under field or greenhouse conditions have monitored but not controlled temperature. Zimmerman (1979) developed a semi-static enclosure technique for collecting plant volatiles in which a Teflon bag was placed over a branch and sealed with Velcro. After removing as much ambient air as practical, zero (hydrocarbon-free) air was pumped into the bag. During sampling, zero air was pumped into the bag at 2 liters. $\min ^{-1}$. Air samples were removed at the same rate and pumped into a stainless-steel cannister. Ohta (1984) collected volatile organics from a variety of plants in the field by placing a Tedlar film bag entirely over the plants for $5 \mathrm{~min}$, then drawing a 2.5-liter volume from the bag through $300 \mathrm{mg}$ of Tenax-GC adsorbent. Winer et al. (1992) suspended a 2-ml Teflon film enclosure over vegetation in the field. Medical breathing air

Received for publication 24 Mar. 1995. Accepted for publication 7 Nov. 1995. University of Florida journal series no. R-04133. We gratefully acknowledge the technical assistance of B.D. Dueben and A.T. Proveaux. The cost of publishing this paper was defrayed in part by the payment of page charges. Under postal regulations, this paper therefore must be hereby marked advertisement solely to indicate this fact.

${ }^{1}$ Predoctorate fellow.

${ }^{2}$ Professor and chair.

${ }^{3}$ Plant physiologist.

${ }^{4}$ Systems engineer.

${ }^{5}$ Research chemist.
(99.6\% stated purity level) was used as the purge gas. This air was bubbled through distilled water to humidify it and $\mathrm{CO}_{2}$ was added to obtain $360 \mathrm{ppm}$. Temperature and relative humidity inside the enclosure were monitored, and air samples were collected onto Tenax-GC adsorbent or Tenax-GC in series with a small amount of Carbosieve. Heath and Manukian (1992) secured a polyester material infused with activated charcoal to one end of a Pyrex glass cylinder and used a blower to push ambient air through the filter. Intact branches from mature cotton (Gossypium hirsutum L.) plants were placed inside the cylinder and air samples were collected from the outlet of the cylinder after the air passed over the stems and leaves.

Tingey et al. (1979) used a gas-exchange chamber placed within a controlled-environment chamber to collect isoprene from potted live oak (Quercus virginiana Mill.) plants under various light and temperature regimes. Due to the absence of a nutrient delivery system, this method was not suitable for long-term studies.

Destructive methods of volatile collection, which require maceration or cutting of plant tissue, preclude the possibility of sampling a plant at various time intervals and may elicit damageinduced volatile compounds. Methods that do not control and monitor environmental conditions during collection periods overlook the influence such conditions may exert on the volatile profile obtained. We did not find literature describing nondestructive sampling of plant volatiles, over a period of days or weeks, that was conducted under controlled environmental conditions. The primary objective of this investigation was to develop a system and methodology for the qualitative and quantitative analysis of volatile emissions from intact plants, sampled over a course of several weeks, and grown under controlled conditions.

\section{Materials and Methods}

Modified growth chamber. A growth chamber (model EF7; Controlled Environments, Winipeg, Canada) was modified to approximate the lighting conditions and hydroponic system used 

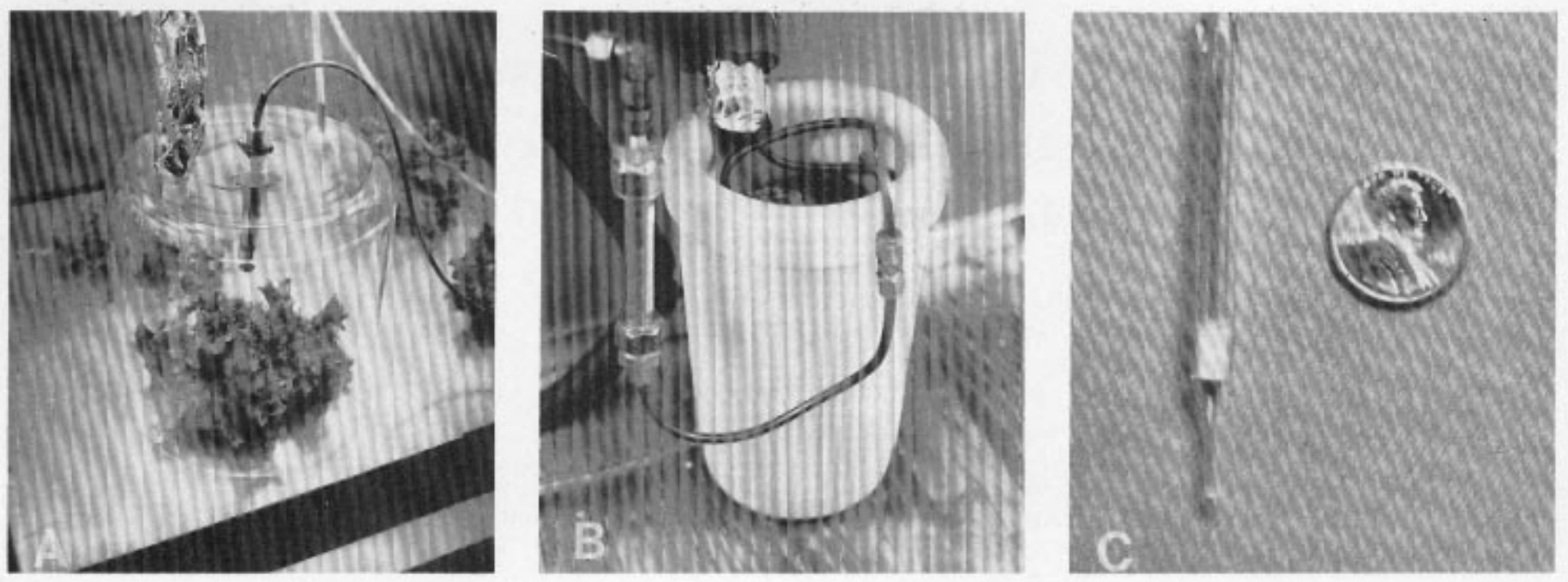

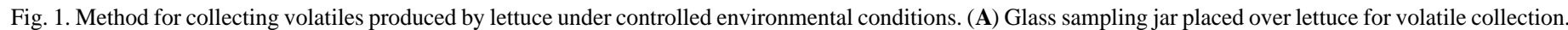
(B) Dewar containing copper tubing in ice water slurry for precooling air entering sampling jar. (C) Volatile collector trap.

in NASA's biomass production chamber (BPC) at Kennedy Space Center. The original incandescent and fluorescent light banks were replaced by three externally mounted ballast-reflector units (Energy Technics Horticulture Lighting, York, Pa.). The two outside units were equipped with 400-W high-pressure sodium lamps (General Electric Co., Cleveland, Ohio) and the center unit contained a 400-W metal halide lamp (Venture Lighting International, Cleveland). The lamps were seated on an aluminum heat-removal duct about $5 \mathrm{~cm}$ high. One pane of 6-mm clear tempered glass was situated at the bottom of the duct and separated the duct from the inside of the growth chamber. A second pane of 6-mm clear tempered glass was positioned midway between the lower pane and the high-intensity discharge (HID) lamps. The plate glass barriers reduced longwave radiation within the growth chamber (Bubenheim et al., 1988; McCree, 1984). The photosynthetic photon flux (PPF) measured with a quantum sensor (model LI185; LI-COR, Lincoln, Neb.) averaged $360 \mu \mathrm{mol} \cdot \mathrm{m}^{-2} \cdot \mathrm{s}^{-1}$ at $6 \mathrm{~cm}$ above the top of the hydroponic trays.

Plants were cultivated in trays using a nutrient film technique. Two acrylic trays $(98 \mathrm{~cm}$ long $\times 20 \mathrm{~cm}$ wide $\times 3.8 \mathrm{~cm}$ deep) were covered by two adjacent $3.2-\mathrm{mm}$ aluminum sheets. Plants were located in each of six $1.9-\mathrm{cm}$ holes separated by $32 \mathrm{~cm}$. Twenty liters of the nutrient solution was contained in an insulated reservoir. A Coolflow-75 chiller (NESLAB Instruments, Portsmouth, N.H.) controlled the nutrient solution temperature by maintaining the temperature of water flowing through a stainless-steel coil immersed in the solution in the reservoir. The nutrient solution temperature was maintained at $23 \pm 2 \mathrm{C}$. Air passing through an aquarium stone aerated the nutrient solution.

A pH controller (model 4505; ICM, Hillsboro, Ore.) and submersible pH electrode (model G-27001-80; Cole-Parmer Instrument Co., Niles, Ill.) monitored the $\mathrm{pH}$ of the nutrient solution; when the $\mathrm{pH}$ increased above 6.1, a chemical pump (model 2105R; March Mfg., Glenview, Ill.) added 2.5\% nitric acid to the nutrient solution to maintain the $\mathrm{pH}$ within the range $5.8 \pm 0.3$.

A modified half-strength Hoagland's no. 1 solution was used to provide macronutrients (Hoagland and Arnon, 1950), and micronutrients were provided at half the concentration described by Johnson et al. (1957).

Cardy ion-selective meters (Fisher Scientific, Orlando, Fla.) were used to monitor $\mathrm{NO}_{3}^{-}$and $\mathrm{K}^{+}$concentrations. Used solution was replaced when the concentration of $\mathrm{NO}_{3}{ }^{-}$or $\mathrm{K}^{+}$was less than $20 \%$ of their values measured in freshly prepared solution. Solution was also replaced at least every 5 to 7 days to minimize bacterial growth in the reservoir.

Volatile collection methodology. Two sizes of Pyrex cylindrical mold-blown glass jars (11.85 and 15.50 liters) with open ends were modified as sampling vessels. The smaller jar was used for sampling plants during early stages of growth and the larger jar was used during later stages.

Each jar was customized to accommodate three ports in its top as shown in Fig. 1A. A relative humidity-temperature transmitter (model HX13V; Omega Engineering, Stamford, Conn.) was suspended through the center port. The other ports were used for sampling and for incoming air.

Measurements of PPF within the jar were obtained for comparing to PPF outside the jar, which averaged $360 \mu \mathrm{mol} \cdot \mathrm{m}^{-2} \cdot \mathrm{s}^{-1}$. PPF was reduced about $7 \%$ in the 11.85 -liter jar and about $8 \%$ in the 15.50-liter jar compared to PPF outside the jars.

Plant volatiles were sampled by placing a glass jar over the plant of interest (Fig. 1A). A flowmeter regulated the flow of air supplied to the jar. The air was pushed through two in-line activated charcoal filters (previously described by Heath et al., 1992), and through 6.4-mm copper tubing fashioned into a coil and submerged in an ice water bath in a dewar. The dewar was situated immediately behind the growth chamber, and one end of the copper tube protruded into the chamber (Fig. 1B). The air then passed through a 1.0-m length of insulated, 6.4-mm-OD Teflon tubing (no. G-06407-44, Cole-Parmer Instrument Co.) and into the glass jar.

The copper coil cooled the purified air before it entered the glass sampling jar, thereby countering heat accumulation during the light cycle. Temperatures within the glass sampling jar were maintained at $23 \pm 1.5 \mathrm{C}$ during the light period and $18 \pm 1.5 \mathrm{C}$ during the dark period. This temperature decrease resulted when the lights were turned off and did not require adjustments to the incoming air flow rate. Generally, the temperatures inside and outside the jar were within $1 \mathrm{C}$ except at the onset of the dark period when the temperature in the jar fell somewhat slower than that outside the jar. 
Air in the sampling jar was sampled by inserting $9 \mathrm{~cm}$ of a 1.2$\mathrm{m}$ length of 6.4-mm-OD Teflon tubing into the jar. The other end of the tubing was attached to a 6.4-mm-OD brass bulkhead union that protruded through the growth chamber. One end of a volatile collector trap (VCT), previously described by Heath et al. (1992) (Fig. 1C), was attached to the brass union. This design permitted VCTs to be changed without opening the growth chamber.

The other end of the VCT was attached with flexible polyvinyl chloride tubing to a flowmeter, which in turn was connected to a vacuum pump. Air sampling through the VCT was maintained at 1.5 liters $\cdot \mathrm{min}^{-1}$ during plant volatile collections.

Environmental data monitoring system. An IBM type 386 personal computer was used to monitor and record continuously the following environmental parameters: 1) temperature in the growth chamber, 2) temperature in the glass sampling jar, 3) relative humidity in the growth chamber, 4) relative humidity in the glass sampling jar, 5) nutrient solution temperature, 6) $\mathrm{CO}_{2}$ concentration in growth chamber, and 7) differential pressure in the glass sampling jar. The data-acquisition control software and hardware components used were described by Manukian and Heath (1993).

Analyses of collected volatile compounds. Volatile collector traps were cleaned with ultra-high-purity gas chromatographymass spectroscopy (GC-MS)-grade methylene chloride before use. After sampling, the VCT was immediately eluted with two 50$\mu \mathrm{l}$ aliquots of the same grade methylene chloride, and $100 \mathrm{ng}$ of dodecan-1-ol acetate (S-C 12:Ac) was added as an internal standard.

Analyses of extracted samples by capillary GC (model 5890, series II; Hewlett-Packard) were conducted on a GC with a cool on-column injector (septum injector) and flame ionization detector (FID). Three columns were connected in series with Glaseal connectors (Supelco, Bellefonte, Pa.), a configuration that permitted injection volumes of 5 to $100 \mu 1$ of the sample-solvent mixture without concentration (Grob, 1982; Murphy, 1989). A 10-cm $\times$ 0.5-mm-ID deactivated fused silica column ( $\mathrm{J} \& \mathrm{~W}$ Scientific, Folsom, Calif.), attached at one end to the injector, was attached at the other end to a $10-\mathrm{m} \times 0.25-\mathrm{mm}-\mathrm{ID}$ deactivated fused silica column ( $\mathrm{J} \& \mathrm{~W}$ Scientific) serving as a retention gap. The third length, a 30-m $\times 0.25$-mm-ID Carbowax Econo-Cap capillary column with a film thickness of $0.25 \mu \mathrm{m}$ (Alltech Associates, Deerfield, Ill.) connected the retention gap and the FID. All primary GC analyses were conducted with the Carbowax column, and, in some cases, a $25-\mathrm{m} \times 0.32-\mathrm{mm}$-ID bonded methyl silicone column with a film thickness of $5.0 \mu \mathrm{m}$ (Quadrex Corp., New Haven, Conn.) was used to provide additional confirmation of results obtained with the Carbowax column.

GC analyses were conducted on injection amounts of 5 to $10 \mu \mathrm{l}$ of the sample-solvent mixture. The initial GC oven temperature was set at $60 \mathrm{C}$ for $5 \mathrm{~min}$, then temperature programed at $10 \mathrm{C} / \mathrm{min}$ up to $180 \mathrm{C}$ where isothermal conditions were maintained for 13 min. Helium at a linear flow velocity of $20 \mathrm{~cm} \cdot \mathrm{s}^{-1}$ was used as the carrier gas. FID detector response was interfaced to a Nelson series 773 AD interface box and processed with Turbochrom III software (Perkin-Elmer Corp., Cupertino, Calif.) operating on an IBM type 386 PC system.

Mass spectra of samples were obtained with a Finnigan ion trap MS. The Carbowax and methyl silicone columns used for routine GC analyses were also used for GC-MS analyses. Spectra of samples were obtained with the MS operating in the electron impact and chemical ionization modes. Isobutane was the reagent gas used for chemical ionization.

Collected compounds were identified by matching the retention times and mass spectra of the natural samples with those of purchased chemicals. (Z)-3-hexenal was purchased from Bedoukian Research (Danbury, Conn.). (E)-2-hexenal, (Z)-3-hexenol, (E)-2hexenol,(E)-3-hexenol, and (E)-2-hexenyl acetate were purchased from Aldrich Chemical Co. (Milwaukee). (Z)-3-hexenyl acetate was purchased from Sigma Chemical Co. (St. Louis). (E)-3hexenyl acetate was synthesized from (E)-3-hexenol. Additional confirmation was obtained by comparison of mass spectra with published data (e.g., Arey et al., 1991; Visser et al., 1979).

Experimental protocol. Before sampling lettuce volatiles, background collections of the air in the sampling jar were completed with no plant present. This was done during light and dark periods. Spot background collections were also done occasionally after plants were in the growth chamber by placing the sampling jar between plants. These procedures allowed identification of chromatographic peaks not produced by the plants.

Germination boxes consisted of opaque acrylic boxes covered with an acrylic lid with three 3-mm slits (Fig. 2). Sterilized Waldmann's 'Green Leaf' lettuce seeds were placed on nylon fabric hanging through each slit into tap water. A second opaque box with three transparent slits was placed inverted on top of the lid. The seeds were germinated in darkness for $48 \mathrm{~h}$ using a 24-h cycle of $8 \mathrm{~h}$ at $18 \mathrm{C}$ and $16 \mathrm{~h}$ at 23C. For the next 2 days, the germination box was exposed to $360 \mu \mathrm{mol} \cdot \mathrm{m}^{-2} \cdot \mathrm{s}^{-1} \mathrm{PPF}$ during each $16-\mathrm{h}$ period. Then for $72 \mathrm{~h}$, the top half of the germination box was removed. A split-block randomized experimental design was used in which a separate germination box was prepared on four consecutive days; at the completion of each 7-day germination interval, a seedling was transplanted into the hydroponic trays. Thus, four single-plant samples of volatile emissions were collected at each time interval from the EF7 chamber, and these time intervals were offset by 1 day. PPF, photoperiod, and temperature were the same as those during germination.

A preliminary experiment was completed to identify periods of the diurnal cycle important for sampling. Continual 4-h collections were conducted over a 28 -h period on a plant 26 days after transplanting. Other collections during various periods of the light and dark cycles were done on younger and older plants.

Plants were sampled at 7, 14, 21, 28, and 32 days after transplanting (DAT). Before sampling, the cooled purified air was allowed to purge the glass collection jar until the temperature

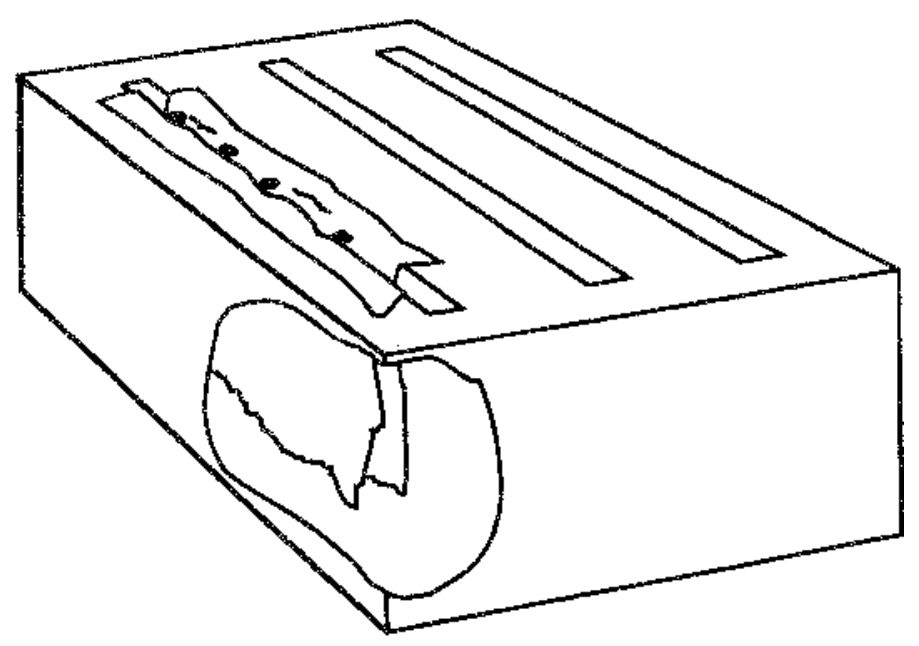

Fig. 2. Germination box for producing seedlings, with cut-out view showing nylon fabric hanging into reservoir. 
Table 1. Volatile compounds identified in headspace samples from 'Waldmann's Green' leaf lettuce (Lactuca sativa L.).

\begin{tabular}{lccc}
\hline \hline Compound $^{\mathrm{z}}$ & Kovats index $^{\mathrm{y}}$ & Major MS (EI) ions & Other evidence \\
\hline (Z)-3-hexenal & 1152 & $41,69,55,83$ & MS (CI); cochromatography \\
(Z)-3-hexenol & 1378 & $41,67,55,82$ & MS (CI); cochromatography \\
(Z)-3-hexenyl acetate & 1315 & $43,67,82$ & MS (CI); cochromatography \\
\hline
\end{tabular}

${ }^{\mathrm{z}}$ Mass spectrum and Kovats index are consistent with that of purchased sample.

${ }^{\mathrm{y}}$ Kovats index determined on a 30-m $\times 0.25$-mm-ID Carbowax Econo-cap capillary column.

inside the jar was $\pm 1 \mathrm{C}$ of the growth chamber setpoint temperature. An inlet airflow of 15.5 liters $\cdot \mathrm{min}^{-1}$ usually was sufficient. Then the jar was placed over the plant $3 \mathrm{~h}$ before the onset of the dark period and left in place without sampling for $1 \mathrm{~h}$. Subsequently, volatiles were collected for 2 -h intervals beginning $2 \mathrm{~h}$ before the dark period began and ending $6 \mathrm{~h}$ later.

To measure possible differential pressure variability in the glass jar during the transition from the light to the dark period, a baratron tube pressure transducer (model 223BD-00010AA; MKS Instruments, Burlington, Mass.) connected to a voltmeter (model HP3437A; Hewlett-Packard, Loveland, Colo.) was used. Differential pressure was measured through a Teflon tube inserted into the glass jar while purified air passed into the jar at 15.5 liters $\cdot \mathrm{min}^{-1}$. The transducer was calibrated to indicate a reading of $0 \mathrm{~cm} \mathrm{H}_{2} \mathrm{O}$ for ambient air outside the growth chamber.

\section{Results and Discussion}

System performance: environmental conditions. Differential pressure measurements obtained during the transition from the light to the dark period did not vary significantly during the temperature change from 23 to $18 \mathrm{C}$. This result was consistent with the fact that, although the air in the glass jar was pressurized relative to external air, there was a significant amount of leakage at each of the three ports on the top of the jar and around its base where it was supported by the aluminum plate. Backflow of contaminants into the jar was prevented by this leakage.

The flow of purified air into the glass jar purged the jar 1 to 1.5 times/min. This continual flushing of the jar minimized accumulation of vapor phase volatile products and the consequent formation of a gradual chemical potential gradient around the leaves. The continual evacuation of airborne compounds may have enhanced volatile emission rates somewhat by increasing the chemical gradient at this interface.

Occurrence and identification of lettuce volatiles. Analyses of air samples collected during the 2 -h period immediately after the end of the light period consistently indicated the presence of three compounds beginning at 21 DAT. None of these compounds was detected during other periods of the diurnal cycle. To confirm that the compounds detected originated from the lettuce and not from the collection system, chromatograms representing background collections in which the glass jar was empty were compared to those from collections in which the jar was placed over a lettuce plant.
The compounds were identified as (Z)-3-hexenal,(Z)-3-hexenol, and $(Z)-3$-hexenyl acetate by comparing their mass spectra with those of known compounds. The natural products and known compounds were analyzed with the MS operating in the electron impact and chemical ionization modes. Additional confirmation of the identification of the plant compounds was obtained by comparing their GC retention times with those of known chemicals (Table 1). The relative amounts of each plant compound are listed in Table 2.

In another lettuce study, Batten et al. (1996) did not detect the three compounds collected in this study, but detected other compounds. In our study, the percentage of air sampled from the jar ( $8 \%$ to $10 \%$ ) may have been too low to detect the compounds found by Batten et al. Arey et al. (1991) noted that (Z)-3-hexenol and (Z)3-hexenyl acetate were often detected in studies that used Tenax as adsorbent, whereas these compounds were not found in samples collected in stainless-steel cannisters. They suggested the possibility of wall adsorption-desorption problems and poor recovery from steel cannisters. Batten et al. used steel cannisters for sample collection, whereas we used Super Q, an adsorbent with properties similar to Tenax. This may explain why (Z)-3-hexenal, (Z)-3hexenol, and (Z)-3-hexenyl acetate were not detected by Batten et al. We did not find other literature describing volatiles measured from intact lettuce plants.

(Z)-3-hexenol and (Z)-3-hexenyl acetate were the most dominant oxygenated hydrocarbons emitted from over 30 agricultural and natural plant species surveyed by Winer et al. (1992). Arey et al. (1991) detected (Z)-3-hexenol and (Z)-3-hexenyl acetate from lettuce under field conditions but did not report any effects of environment on emission rates. (Z)-3-hexenal has been detected in emissions from tomato (Lycopersicon esculentum $\mathrm{L}$.) leaves (Buttery et al., 1987). The headspace of juice removed from lettuce with a sieve and extractor contained the isopropyl, sec-butyl, and isobutyl forms of 3-alkyl-2-methoxypyrazine (Murray and Whitfield, 1975). The presence of these compounds in headspace samples over undamaged lettuce has not been reported.

In this study, the nondestructive sampling of volatile compounds emitted by lettuce plants was achieved in the controlled environment of a growth chamber. The continuous purging of the air in the sample jar was a limitation in that it reduced the system's ability to detect low-level emissions. Nonetheless, three volatile compounds were collected up to 32 DAT from intact lettuce plants cultivated under controlled environmental conditions.

Table 2. Relative percentage of compounds emitted by 'Waldmann's Green' leaf lettuce (Lactuca sativa L.).

\begin{tabular}{lccc}
\hline \hline & \multicolumn{3}{c}{ Mean percentage of total volatiles collected at specified day after transplanting $($ DAT) } \\
\cline { 2 - 4 } Compound & 21 & 28 & 32 \\
\hline (Z)-3-hexenal & $14.1 \pm 7.3$ & $17.1 \pm 5.6$ & $22.2 \pm 7.4$ \\
(Z)-3-hexenol & $46.1 \pm 9.5$ & $35.9 \pm 6.6$ & $28.8 \pm 5.6$ \\
(Z)-3-hexenyl acetate & $39.8 \pm 11.1$ & $47.0 \pm 9.0$ & $49.0 \pm 11.4$ \\
\hline
\end{tabular}

${ }^{\mathrm{z}}$ Mean percentage of total volatile emissions \pm standard deviation. 


\section{Literature Cited}

Arey, J., A.M. Winer, R. Atkinson, S.M. Aschmann, W.D. Long, and C.L. Morrison. 1991. The emission of (Z)-3-hexen-1-ol,(Z)-3-hexenylacetate, and other oxygenated hydrocarbons from agricultural species. Atmos. Environ. 25:1063-1075.

Batten, J.H., G.W. Stutte, and R.W. Wheeler. 1996. Volatile organic compounds detected in the atmosphere of NASA's biomass production chamber. In: Advances in space research. Pergamon Press, New York.

Bubenheim, D.L., B. Bugbee, and F.B. Salisbury. 1988. Radiation in controlled environments: Influence of lamp type and filter material. J. Amer. Soc. Hort. Sci. 113:468-474.

Buttery, R.G., and L.C. Ling. 1984. Corn leaf volatiles: Identification using tenax trapping for possible insect attractants. J. Agr. Food Chem. 32:1104-1106

Buttery, R.G., L.C. Ling, and D.M. Light. 1987. Tomato leaf volatile aroma components. J. Agr. Food Chem. 35:1039-1042.

Buttery, R.G., C. Xu, and L.C. Ling. 1985. Volatile components of wheat leaves (and stems): Possible insect attractants. J. Agr. Food Chem. $33: 115-117$.

Grob, J.J. 1982. Band broadening in space and the retention gap in capillary gas chromatography. J. Chromatog. 237:15-23.

Heath, R.H., P.J. Landolt, B. Dueben, and B. Lenczewski. 1992. Identification of floral compounds of night-blooming jessamine attractive to cabbage looper moths. Environ. Entomol. 21:854-859.

Heath, R.R., and A. Manukian. 1992. Development and evaluation of systems to collect volatile semiochemicals from insects and plants using a charcoal-infused medium for air purification. J. Chem. Ecol. 18:12091226.

Hoagland, D.R., and D.I. Arnon. 1950. The water-culture method for growing plants without soil. Calif. Agr. Expt. Sta. Cir. 347.

Johnson, C.M., P.R. Stout, T.C. Broyer, and A.B. Carlton. 1957. Com- parative chlorine requirements of different plant species. Plant and Soil $8: 337$.

Manukian, A., and R.R. Heath. 1993. Development of an automated system to simultaneously collect volatiles and monitor environmental conditions for use in life sciences research. Sci. Comp. Aut. 9:27-40.

McCree, K.J. 1984. Radiation levels in growth chambers fitted with high intensity discharge lamps, with or without thermal barriers. Crop Sci. 24:816-819.

Murphy, R.E. 1989. The fractionation gap: An optimized coupling of used silica columns in open tubular gas chromatography. MS thesis. Univ. of Florida, Gainesville.

Murray, K.E., and F.B. Whitfield. 1975. The occurrence of 3-alkyl-2methoxypyrazines in raw vegetables. J. Sci. Food. Agr. 26:973-986.

Ohta, K. 1984. Emission of hexenol from higher plants. Geochem. J. 18:135-141.

Tingey, D.T., M. Manning, L.C. Grothaus, and W.F. Burns. 1979. The influence of light and temperature on isoprene emission rates from live oak. Physiol. Plant. 47:112-118.

Visser, J.H., S. Van Straten, and H. Maarse. 1979. Isolation and identification of volatiles in the foliage of potato, Solanum tuberosum, a host plant of the Colorado beetle, Leptinotarsa decemlineata. J. Chem. Ecol. 5:13-25.

Winer, A.M., J. Arey, R. Atkinson, S.M. Aschmann, W.D. Long, C.L. Morrison, and D.M. Olszyk. 1992. Emission rates of organics from vegetation found in California's Central Valley. Atmos. Environ. 26A:2647-2659.

Zimmerman, P.R. 1979. Determination of emission rates of hydrocarbons from indigenous species of vegetation in the Tampa/St. Petersburg, Florida area. In Final Appendix C, Tampa Bay area photochemical oxidant study. EPA-904/9-77-028, U.S. Environmental Protection Agency, Region IV, Atlanta. 